\title{
Cross-sectional study of drivers of animal- source food consumption in low-income urban areas of Nairobi, Kenya
}

Laura Cornelsen ${ }^{1,2^{*}}$ D, Pablo Alarcon ${ }^{2,3}$, Barbara Häsler ${ }^{2,3}$, Djesika D. Amendah ${ }^{4}$, Elaine Ferguson ${ }^{1}$, Eric M. Fèvre ${ }^{5,6}$, Delia Grace ${ }^{6}$, Paula Dominguez-Salas ${ }^{2,3,6+}$ and Jonathan Rushton ${ }^{2,3+}$

\begin{abstract}
Background: Malnutrition, including undernutrition and micronutrient deficiencies is a chronic problem in most developing countries. Animal-source foods (ASFs) provide essential sources of proteins and micronutrients, yet little is known about ASF consumption patterns or household preferences towards animal-source products among low-income populations. This is particularly critical for malnourished children for whom even small increases in consumption could help improve nutrition and health outcomes. This study analysed both the demand as well as the drivers and barriers for ASF consumption among households in two low-income areas in Nairobi, Kenya.
\end{abstract}

Methods: Data on ASF expenditures and quantities purchased in the previous week, and reasons for consuming or not consuming ASFs were collected in a cross-sectional study from 205 randomly selected households in Korogocho and Dagoretti settlements. Self-reported reasons for consuming or not-consuming ASFs were described. Demand for ASFs was estimated using the Almost Ideal Demand System to provide measures of demand elasticity for changes in food prices and expenditures.

Results: On average households purchased 48 grams of ASFs, including fresh milk, per week per household member. Expenditure on ASFs counted for 38\% (520 Kenyan Schillings) of the overall food expenditure of which, on average, $48 \%$ was spent on fresh milk. Price was the most commonly self-reported barrier for consumption, while taste was reported as the main driver for consumption. The perceived nutritional value was an important driver for consuming more commonly purchased ASFs (beef, eggs, fish and milk). For less commonly purchased ASFs (pork, sausages, sheep and goat meat, offal) taste, access and tradition were given as main reasons for not consuming. Estimated demand elasticities indicated that increases in total food expenditure would lead to greatest increase in the demand for beef meat. Price reductions would increase the demand relatively more for fish, other meats and dairy.

Conclusions: For most ASFs better affordability would be a clear driver to increase the consumption. However, to increase the variety and quantity of ASFs eaten, other policies targeting improvements in physical access, food safety and consumer education on nutritional values and cooking methods should be considered.

Keywords: Animal-source foods, Price elasticity of demand, Food choice, Intervention, Malnutrition, Nairobi, Informal settlements

\footnotetext{
* Correspondence: laura.cornelsen@lshtm.ac.uk

${ }^{\dagger}$ Equal contributors

'London School of Hygiene and Tropical Medicine, Keppel Street, London

WC1E 7HT, UK

${ }^{2}$ Leverhulme Centre for Integrated Research on Agriculture and Health, 36

Gordon Square, London WC1H OPD, UK

Full list of author information is available at the end of the article
} 


\section{Background}

Despite improvements in child malnutrition in Kenya since the early 1990's, the rate of undernourished children remains high. Nationally $35 \%$ of under 5 year olds are stunted, $16 \%$ underweight and $7 \%$ wasted $[1,2]$. In urban informal settlements, prevalence of stunting among under 5 year old children can be even higher, and has been reported to exceed $40 \%$ [1, 3, 4]. Elsewhere, it has been suggested that nearly half (48\%) of Nairobi's households living in informal settlements are food-insecure with both adult and child hunger [5].

Historically, diets in Kenya have been cereal based, with additions of a variety of vegetables, fruits and tubers, when available, but containing very little animalsource foods (ASFs) [6]. According to the World Food Program consumption score, $16 \%$ of households in Nairobi were classified into the borderline or poor food consumption groups, indicating food insecurity, and were, in general found to have low intake of milk and animal-source foods (ASFs) [7].

While the supply of ASFs, including meat, milk and eggs has been steadily growing in African countries since the early 1990s [8, 9], including in Kenya [10], consumption inequalities are high. Based on the 2005-06 Kenyan household survey data, the poorest tercile consumed $35 \mathrm{~g}$ of protein (from all sources) per capita/day, whereas households in the wealthiest tercile consumed $81 \mathrm{~g}$ [11]. In Nairobi, households in the highest income quintile consumed annually nearly three times more of beef, chicken and eggs (46 kg per capita) as the households in the lowest quintile (16 kg per capita) [12].

Micronutrient intake from ASFs is critical for vulnerable populations, and in particular for undernourished children [13]. ASFs are relatively expensive sources of energy but provide high quality, readily digested protein, and essential micronutrients for normal development and good health [13-15]. Bioavailable micronutrients found in ASFs, and in meat specifically, are difficult to obtain in adequate quantities from plant source foods alone $[13,16]$. Recent reviews of literature in lowincome countries in general, and observational and interventional studies from Kenya, have concluded that increased consumption of milk and other ASFs by undernourished children improved anthropometric indices, cognitive function and school performance, while reducing also morbidity and mortality [6, 13, 17-20]. In addition, ASF consumption has also been found to have a positive impact on the quality of diets for women, and specifically for pregnant and breastfeeding women [13].

Poverty is often cited as the most prominent reason for the lack of ASFs in the diet in developing countries [13]. Most recent and comprehensive study examining the demand sensitivity to prices and income changes in Nairobi, found that poor households spent a greater share of the total food expenditure on staples such as maize, sugar and also vegetables while non-poor households spent more on wheat, rice, and ASFs (dairy and dairy products, beef, poultry). They also found more sensitive demand with respect to changes in prices and incomes among poor households for dairy, vegetables, fruits, sugar, poultry, beef, wheat and rice. [21] Another study looked at the demand for small ruminant meat specifically focusing on areas (including in Nairobi) near a slaughterhouse of sheep and goats [22]. They found that the price of meat, income and perception of the quality of the meat were important factors influencing the probability of the demand for such meat.

Other factors, such as taste, perceived nutritional value of foods, cultural beliefs, food taboos and food safety concerns may have an important role in the ultimate choice of the type and quantity of foods consumed, particularly in the ASF context. Consumption of meat products for example is prone to cultural and other beliefs [23], which potentially affects more women and children [24]. Together with price and income, these drivers are also more likely to be significant in dynamic and rapidly changing urban centres where availability of diverse foods is better due to easier access to markets and large populations influencing demand. Understanding these broad range of drivers in ASF choices is even more critical, but little studied, among poor and vulnerable populations because of their relatively lower food budgets and thus limited possibilities for diversifying food consumption.

This study is part of a comprehensive pilot project "Investigation of the relationship between livestock value chains and nutritional status of women and children: a pilot study in Kenya". The aim of the project was to inform research and design of interventions in livestock value chain to address the low consumption of ASFs among vulnerable populations, and in particular, the large share of chronically malnourished young children. Among other the study collected data from 205 households on a) dietary intake using a $24 \mathrm{~h}$ recall questionnaire and nutrition outcomes, b) household expenditures on ASFs, and c) stated reasons for regularly consuming or not consuming the ASF products.

Dominguez-Salas et al. (2016) investigated the dietary intake data and nutrition outcomes among the children and women [25]. They found the households' diet to be consisting predominantly of starchy staples (e.g., rice, ugali (maizemeal), pulses, and vegetables (e.g., tomato, cabbage, carrot), including green leaves such as kale (more than $80 \%$ of women and children were reported to have eaten these during the previous $24 \mathrm{~h}$ ). Consumption of ASFs was limited; dairy was consumed on average by $>65 \%$ of women and children but other ASFs, such as eggs, meat and fish products were consumed by 
less than $30 \%$ of women and children during the previous $24 \mathrm{~h}$. Malnutrition was evident as $4.4 \%$ of children aged 1-3 years were wasted and further $41.5 \%$ stunted. Anaemia was found in $74.1 \%$ of children and $26 \%$ of women. Among women, mild or moderate undernutrition was recorded for $7.3 \%$ while $29.1 \%$ were overweight, including $9.9 \%$ obese [25].

The aim of this study was to analyse the demand for and the drivers and barriers of ASF consumption among these households to understand in detail what types of ASFs household consume, and why they consume some of the ASFs and not others. The study contributes to informing research and design of interventions in livestock value chain to improve ASF consumption in the diets of vulnerable populations.

\section{Methods}

\section{Household survey data}

A cross-sectional survey, including the sections used in this study on household ASF expenditures and stated reasons for consumption, was carried out in Dagoretti (low-income neighbourhood) and Korogocho (informal settlement ${ }^{1}$ ), in Nairobi from December 2013 to February 2014, during the rainy season (excluding the last week of December and first week of January) [25]. The survey was conducted among 205 randomly selected households based on Global Positioning System (GPS) positions. ${ }^{2}$ Once the GPS point was identified, the closest household to the right when facing north was selected. If the first household was not eligible, then the next one on the right was selected. Eligibility criteria were: informal housing (temporary) structures; households with low monthly income (below 20,000 Kenyan Schillings (KES), i.e., \$US230) according to estimated incomes for manual workers); presence of at least one child between 1 and 3 years of age; and, a non-pregnant woman of reproductive age (15-45 years) [25].

The questionnaires were administered by trained interviewers $^{3}$ in Swahili to the person in charge of food purchasing and preparation in the household. The responses were captured electronically in Android tablets with the open-source tool Open Data Kit (ODK Collect) [25].

Household expenditure on ASF products was assessed, by asking the respondents: 'During the week preceding the survey a) how much did you spend on the following products? b) what was the quantity purchased? c) what was the total expenditure on all foods?'. The ASF products included beef, beef green offal (i.e., intestines and stomachs, and asked as 'matumbo' to participants), beef red offal (liver, lungs, etc., and asked as 'organs'), beef sausages, pork, pork sausages, black pudding ('mutura'), mutton, goat meat, sheep and goat green offal, sheep and goat red offal, indigenous chicken, broiler chicken, fish (including dried fish 'omena'), eggs, fresh cows' milk and yoghurt, fermented cows' milk ('mala'), and sheep or goat fresh milk. All quantities were standardised to grams and expenditures were recorded in Kenyan Shillings (KES).

The respondents were also asked to state how frequently they generally consumed each of the ASF and provide the two main reasons for consuming or not consuming these. Based on the responses the reasons were coded into following categories: 'taste,' 'price,' 'tradition', 'nutrition', 'physical access', 'hygiene', 'product presentation', 'risk of disease, 'other reasons' (to be specified) or 'don't know'.

We used two approaches to analyse the data. We first described the expenditure patterns across the individual ASFs and analysed the stated reasons for consuming and not consuming each of the ASFs. The stated reasons were analysed as mean proportions of respondents among those who did and did not consume the ASF, respectively. Secondly, we estimated the demand for most commonly eaten ASFs using a two-step censored demand system (described below) to obtain estimates demand elasticities as indicators of consumption sensitivity to changes in ASF prices and food expenditure.

\section{Censored two-step demand system}

ASFs were categorised into five groups for demand estimation: beef, dairy (including fresh and fermented milk and yoghurt), eggs, fish (including dried fish), and 'other meats' (processed meats, offal, broiler chicken, indigenous chicken, pork, goat and mutton meat) because the share of households purchasing each of the ASFs was low for many products and the budget shares were relatively small. Two households who had not purchased any ASFs during the previous week were removed from the demand analysis and for the purposes of the demand analysis, the final sample size was 203 households.

As an estimate of prices, we calculated unit values as a ratio of expenditure to the quantity purchased for each ASF group. We assumed that households living in the same area (Dagoretti or Korogocho, respectively) were very likely to face the same prices during the survey week and replaced missing unit values for products that households had not purchased in the previous week with average unit values in the two areas in the survey month for each the ASF groups. To deal with quality effects arising from aggregating products of different quality into the same group (e.g., different types of fish) we used the approach by Cox and Wohlegant (1986) [26]. We regressed the log of unit values on household characteristics (income category, household size, share of male adults, education level of the head of the household, whether the household owns their property or lives in a rented space, whether the household owns animals and 
the area in combination with the survey month) and estimated quality adjusted prices by summing the constant term of the regression and the predicted residuals.

Censoring is a common problem in cross-sectional data. As the period of studying expenditures was short, the data included many zero-observations (i.e., nonpurchases) for most ASFs even after aggregation. These could have occurred due to various reasons, including non-consumption due to preference or taste, lack of access, lack of income, high price, or infrequency of consumption. Including such zero-purchases in the analysis without adjustment would lead to significant bias in the demand estimates [27, 28]. To address the censoring problem we employed a two-step sample selection approach proposed by Shonkwiler and Yen (1999) (SY) [28].

In the first step the dichotomous decision of each household to purchase ASFs $\left(I_{i h}\right)$, was regressed on household total ASF expenditure and demographic variables using a probit model:

$$
I_{i h}=\alpha_{i o}+\beta_{i} \log \left(X_{h}\right)+\sum_{b=1}^{k} \rho_{i b} H_{h b}+\varepsilon_{i h}
$$

Where $I_{i h}=1$ if the expenditure share of ASF $w_{i h}>0$ and $I_{i h}=0$ if $w_{i h}=0$ for household $h$ and ASF group $i$. Expenditure shares of the ASFs $\left(w_{i h}\right)$ were found as the ratio of expenditure on individual ASF group to the total household expenditure on ASFs $\left(X_{h}\right)$. The demographic variables $\left(H_{h b}\right), b=1, \ldots, k$ included household size, share of male adults in the household, variables describing sex and education level of the head of the household, whether the household owns their property or lives in a rented space, whether the household owns animals and the area (Korogocho or Dagoretti) where the household resided in combination with the survey month. From the probit model (1) we estimated the normal probability density function $\left(p d f\left(\phi_{i h}\right)\right)$, and the normal cumulative distribution function $\left(c d f\left(\Phi_{i h}\right)\right)$ of the predicted values that were subsequently used in the second step.

In the second step the demand for ASFs was estimated using the Almost Ideal Demand System (AIDS) [29]. We focused on the last step in the budgeting process where consumers allocate the total budget for ASF foods between the individual ASF groups. Generally, the steps that precede this are a) allocation of the budget between food and non-food expenditure, and b) allocating the food budget between ASFs and all other remaining foods. We focused only on the ASFs due to lack of price and quantity information on non-ASFs. ${ }^{5}$ Hence, we assumed weak separability between ASF and other foods, implying that price changes of ASF foods affect expenditure decisions of ASF foods only and estimated elasticities are subsequently conditional on the expenditure of all remaining foods and non-food items. While this assumption has been made by previous studies examining meat demand in Kenya [30] it limits the interpretability of the findings and could have introduced potential bias [31].

The estimated $p d f\left(\phi_{i h}\right)$ and $c d f\left(\Phi_{i h}\right)$ from the first step were incorporated to AIDS to account for the sample selection bias [28] such that:

$$
\begin{aligned}
& w_{i h}=\Phi_{i h} *\left[\alpha_{i}+\sum_{j=1}^{n} \gamma_{i j} \log \left(p_{h j}\right)+\beta_{i} \log \left(\frac{X_{h}}{P}\right)+\sum_{d=1}^{f} \rho_{i d} H_{h d}\right] \\
& \quad+\lambda_{i} \phi_{i}+\varepsilon_{i}
\end{aligned}
$$

Where in addition to above, $p_{h j}$ denote the prices of the ASFs, household demographic variables $\left(H_{h d}\right), d=1$, ..., $f$ included the household size, sex of the head of the household and area of residing in combination with survey month, and $P$ was a price index [32]:

$$
\begin{aligned}
\log (P)=\alpha_{0} & +\sum_{i=1}^{n} \alpha_{i} \log \left(p_{i}\right) \\
& +\frac{1}{2} \sum_{i=1}^{n} \sum_{j=1}^{n} \gamma_{i j} \log \left(p_{i}\right) \log \left(p_{j}\right)
\end{aligned}
$$

Finally, it can be argued that the system identified in [2] suffers from endogeneity if household total ASF expenditure is jointly determined with budget shares for ASF groups. This in turn would lead to inconsistent estimates of the budget share equations. We used the approach by Blundell and Robin [33] whereby total household ASF expenditure $\left(X_{h}\right)$ was regressed on the same set of household demographic variables as in [1] and additionally the income category. The predicted values from this model were employed as approximations of total ASF expenditure $\left(X_{h}\right)$ in [2]. To estimate [2], restrictions of symmetry, and homogeneity were imposed such that:

$$
\gamma_{i j}=\gamma_{j i}, \quad \sum_{j} \gamma_{i j}=0
$$

Yen et al. (2002) showed that the additional adding-up restrictions do not hold when the SY approach is used. Furthermore, they showed that the demand system is correctly estimated using all expenditure share equations instead of dropping one as is done when adding-up restrictions are imposed [34, 35]. Thus, the demand system (2), comprising of five expenditure share equations, was estimated via iterated feasible generalised non-linear least squares (IFGNLS) with robust standard errors, equivalent to maximum likelihood estimation.

In order to estimate the responsiveness of the demand to changes in prices Marshallian elasticities (unconditional of purchase) were calculated from [2] according to $[34,36,37]$ at sample means:

Expenditure elasticity (the \% change in demand due to $1 \%$ change in total ASF expenditure): 


$$
\epsilon_{i}=\overline{\Phi_{i}} *\left(\frac{\beta_{i}}{\bar{w}_{i}}\right)+1
$$

Price elasticity (the \% change in demand due to $1 \%$ change in ASF price):

$$
e_{i j}=\bar{\Phi}_{i} *\left(\frac{\gamma_{i j}}{\bar{w}_{i}}-\frac{\beta_{i}}{\bar{w}_{i}}\left(\alpha_{j}+\sum_{k=1}^{n} \gamma_{k j} \log \bar{P}_{k}\right)\right)-\delta_{i j}
$$

Where $\delta_{i j}=1$ if $i=j$ and 0 otherwise.

Finally, we also estimated total food expenditure elasticities of the ASFs. We followed the procedure shown in Taniguchi and Chern (2000) and estimated the overall ASF demand elasticity $(e)$ to total food expenditure from a simple Working-Leser model regressing total ASF expenditure on total food expenditures, Laspeyers price index (ASFs) and household demographic variables as listed in (1). ASF demand elasticity to total food expenditure was estimated by as $E_{i}=e^{*} \epsilon_{i}$. All data analyses were done using Stata 14 software.

\section{Results}

\section{Sample profile}

Main characteristics of the households are presented in Table $1 .^{6}$ The average household income was low. More than half of the households (54\%) earned less than KES 5,000 in a month ( $<60$ \$USD); which is below the average gross monthly national income per capita of KES 6,354 (2011) [38]. A large share of the households with an income $<5,000$ KES lived in the Korogocho informal settlement (66\%).

The majority of the households $(75 \%)$ had a male head. From the heads of the households, $40 \%$ had primary education only. Majority of the heads of households were Christian (98\% head of households) and 2\% were Muslims [25]. The average number of members in a household was five of which typically two or three were children.

Most households in both areas lived in a rented property with only $14 \%$ and $17 \%$ of households reporting that they owned their property in Korogocho and Dagoretti, respectively. Slightly less than a third of households reported keeping animals with the large majority of these residing in Dagoretti (53 households). Poultry was the most common livestock species (23\% of households). Most households had a cooker (94\%) but only two households had a refrigerator [25].

\section{Expenditure on and price of ASFs}

The average household expenditure on all foods in the previous week was 1,372 KES of which 520 KES (38\%) was spent on ASF (Table 2). On average, households bought 3.5 ASF products in the previous week.
Table 1 Socio-economic and demographic characteristics of

\begin{tabular}{|c|c|c|c|}
\hline Variable & Categories & Mean & SD \\
\hline \multirow[t]{4}{*}{ Area/month ${ }^{\mathrm{a}}$} & Dagoretti/December'13 & 0.296 & 0.457 \\
\hline & Dagoretti/January'14 & 0.197 & 0.399 \\
\hline & Korogocho/January'14 & 0.143 & 0.351 \\
\hline & Korogocho/February'14 & 0.365 & 0.482 \\
\hline \multirow{2}{*}{$\begin{array}{l}\text { Sex of the head of } \\
\text { the household }\end{array}$} & Female & 0.251 & 0.435 \\
\hline & Male & 0.749 & \\
\hline \multirow{3}{*}{$\begin{array}{l}\text { Education of the head } \\
\text { of the household }\end{array}$} & Primary education & 0.414 & 0.494 \\
\hline & $\begin{array}{l}\text { Secondary, technical } \\
\text { skills, college }\end{array}$ & 0.365 & 0.482 \\
\hline & Not known/none ${ }^{c}$ & 0.222 & 0.416 \\
\hline \multirow{4}{*}{$\begin{array}{l}\text { Level of household } \\
\text { income }\left(\mathrm{KES}^{\mathrm{b}}\right)^{\mathrm{a}}\end{array}$} & Less than $1,000(<11.5 \$)$ & 0.064 & 0.245 \\
\hline & $1,001-5,000(11.5-58 \$)$ & 0.463 & 0.450 \\
\hline & $5,001-10,000(58-116 \$)$ & 0.330 & 0.471 \\
\hline & $10,001-20,000(116-232 \$)$ & 0.143 & 0.351 \\
\hline \multirow{2}{*}{$\begin{array}{l}\text { Does the household } \\
\text { own their property }\end{array}$} & Rented & 0.847 & 0.361 \\
\hline & Owned (or parents owned) & 0.153 & \\
\hline \multirow{2}{*}{$\begin{array}{l}\text { Does the household own } \\
\text { animals (excluding pets) }\end{array}$} & Yes & 0.291 & 0.486 \\
\hline & No & 0.709 & \\
\hline $\begin{array}{l}\text { Average number of } \\
\text { household members }\end{array}$ & & 5 & 2.2 \\
\hline $\begin{array}{l}\text { Share of male adults } \\
\text { in the household }\end{array}$ & & 0.218 & 0.123 \\
\hline $\begin{array}{l}\text { Average number of } \\
\text { children in the household }\end{array}$ & & 2.6 & 1.7 \\
\hline
\end{tabular}
the sample $(n=203)$

Nearly all households (91\%) purchased milk in the previous week, which accounted on average for $47 \%$ of all the total ASF expenditure. Half of the households also purchased eggs and beef, accounting on average for $20 \%$ of total ASF expenditure. Fish (including dried) was bought by approximately one third of households. Remaining ASFs were bought by less than $20 \%$ of the households. Beef green offal was most common from offals (bought by $17 \%$ of households). Black pudding and beef sausage were the most popular products from processed products but nonetheless were purchased only by a little more than a tenth of the households.

Processed products (black pudding, dried fish, and beef sausage) had the highest unit price, followed by beef and other meats. Red offals were more expensive than green offals. Goat meat and indigenous chicken were the more expensive meats, followed by beef, sheep and pork. Broiler chicken had the lowest price of the meats.

When considering household size, the ASF consumption per member was very small (assuming equal intra- 
Table 2 Frequency of purchases of ASF by households $(n=203)$

\begin{tabular}{|c|c|c|c|c|c|c|}
\hline$n=203$ & $\begin{array}{l}\text { Exp. share (\%) of } \\
\text { total ASF (SD) }\end{array}$ & $\begin{array}{l}\text { Expen-diture } \\
\mathrm{KES}^{\mathrm{a}} / \mathrm{w}(\mathrm{SD})\end{array}$ & $\begin{array}{l}\text { Unit value (price) } \\
\text { KES/g (SD) }\end{array}$ & $\begin{array}{l}\text { Quantity g/w } \\
\text { (SD) }\end{array}$ & $\begin{array}{l}\text { Quantity per HH } \\
\text { member g/w (SD) }\end{array}$ & $\begin{array}{l}\text { Participation } \\
\text { (SD) }\end{array}$ \\
\hline \multirow[t]{2}{*}{ Cow fresh milk } & 0.470 & 211.41 & 0.090 & 2923.29 & 682.58 & 0.906 \\
\hline & $(0.288)$ & $(170.32)$ & $(0.087)$ & $(2684.79)$ & $(794.66)$ & $(0.292)$ \\
\hline \multirow[t]{2}{*}{ Beef meat } & 0.124 & 94.53 & 0.346 & 285.96 & 66.40 & 0.433 \\
\hline & $(0.173)$ & (171.11) & (0.089) & $(532.80)$ & $(125.01)$ & $(0.497)$ \\
\hline \multirow[t]{2}{*}{ Eggs } & 0.082 & 36.74 & 0.230 & 162.76 & 36.17 & 0.562 \\
\hline & $(0.141)$ & $(56.03)$ & $(0.038)$ & $(246.41)$ & (57.59) & $(0.497)$ \\
\hline \multirow[t]{2}{*}{ Fish } & 0.073 & 29.80 & 0.222 & 174.58 & 44.35 & 0.276 \\
\hline & $(0.169)$ & (83.15) & $(0.197)$ & $(367.63)$ & (95.98) & $(0.448)$ \\
\hline \multirow[t]{2}{*}{ Broiler chicken } & 0.047 & 30.99 & 0.277 & 110.03 & 26.99 & 0.172 \\
\hline & $(0.126)$ & $(108.37)$ & $(0.190)$ & (370.43) & $(98.28)$ & $(0.379)$ \\
\hline \multirow[t]{2}{*}{ Beef green offal } & 0.032 & 23.15 & 0.223 & 113.30 & 27.93 & 0.172 \\
\hline & $(0.078)$ & $(64.79)$ & $(0.086)$ & (330.16) & $(86.83)$ & $(0.379)$ \\
\hline \multirow[t]{2}{*}{ Dried fish (omena) } & 0.028 & 6.49 & 0.441 & 16.09 & 3.79 & 0.124 \\
\hline & $(0.102)$ & $(22.06)$ & $(0.158)$ & $(60.96)$ & (14.59) & $(0.330)$ \\
\hline \multirow[t]{2}{*}{ Cow yoghurt } & 0.022 & 14.83 & 0.206 & 87.03 & 20.52 & 0.172 \\
\hline & $(0.059)$ & $(41.55)$ & $(0.115)$ & (246.38) & $(56.86)$ & $(0.379)$ \\
\hline \multirow[t]{2}{*}{ Pork meat } & 0.021 & 9.21 & 0.306 & 32.51 & 7.78 & 0.079 \\
\hline & $(0.102)$ & (34.69) & $(0.070)$ & (130.13) & $(31.38)$ & $(0.270)$ \\
\hline \multirow[t]{2}{*}{ Black pudding } & 0.016 & 3.84 & 0.573 & 7.06 & 1.80 & 0.118 \\
\hline & $(0.070)$ & $(14.49)$ & $(0.093)$ & $(26.38)$ & $(7.06)$ & $(0.324)$ \\
\hline \multirow[t]{2}{*}{ Beef sausage } & 0.014 & 8.82 & 0.426 & 20.26 & 4.19 & 0.148 \\
\hline & $(0.055)$ & $(36.43)$ & $(0.105)$ & $(79.55)$ & $(14.76)$ & $(0.356)$ \\
\hline \multirow[t]{2}{*}{ Indigenous chicken } & 0.013 & 14.04 & 0.351 & 43.65 & 11.53 & 0.044 \\
\hline & $(0.073)$ & $(82.84)$ & $(0.194)$ & $(243.20)$ & $(66.39)$ & $(0.206)$ \\
\hline \multirow[t]{2}{*}{ Goat meat } & 0.013 & 8.55 & 0.378 & 23.89 & 5.13 & 0.049 \\
\hline & $(0.065)$ & $(43.65)$ & $(0.090)$ & $(125.99)$ & $(27.12)$ & $(0.217)$ \\
\hline \multirow[t]{2}{*}{ Beef red offal } & 0.011 & 10.76 & 0.378 & 28.33 & 6.64 & 0.059 \\
\hline & $(0.050)$ & $(47.91)$ & $(0.133)$ & $(122.37)$ & $(28.58)$ & $(0.236)$ \\
\hline \multirow[t]{2}{*}{ Cow fermented milk } & 0.011 & 3.30 & 0.084 & 36.89 & 9.69 & 0.074 \\
\hline & $(0.050)$ & $(17.10)$ & $(0.029)$ & $(156.00)$ & $(45.80)$ & $(0.262)$ \\
\hline \multirow[t]{2}{*}{ Sheep/goat fresh milk } & 0.010 & 1.58 & 0.147 & 9.04 & 2.75 & 0.010 \\
\hline & $(0.096)$ & $(19.84)$ & $(0.069)$ & $(104.10)$ & $(33.87)$ & $(0.099)$ \\
\hline \multirow[t]{2}{*}{ Pork sausage } & 0.008 & 5.10 & 0.294 & 16.93 & 3.42 & 0.064 \\
\hline & $(0.036)$ & $(27.39)$ & $(0.121)$ & $(85.78)$ & $(17.78)$ & $(0.245)$ \\
\hline \multirow[t]{2}{*}{ Sheep and goat green offal } & 0.004 & 3.79 & 0.168 & 25.62 & 6.18 & 0.030 \\
\hline & $(0.022)$ & $(24.51)$ & $(0.073)$ & $(163.60)$ & $(40.20)$ & $(0.170)$ \\
\hline \multirow[t]{2}{*}{ Sheep meat } & 0.002 & 2.36 & 0.340 & 7.39 & 1.54 & 0.010 \\
\hline & $(0.024)$ & $(24.09)$ & $(0.085)$ & $(78.32)$ & $(18.07)$ & $(0.099)$ \\
\hline \multirow[t]{2}{*}{ Sheep and goat red offal } & 0.001 & 0.44 & 0.750 & 0.69 & 0.13 & 0.010 \\
\hline & $(0.006)$ & $(4.48)$ & $(0.354)$ & $(7.55)$ & (1.36) & $(0.099)$ \\
\hline \multirow[t]{2}{*}{ Total ASF } & & 519.8 & & & & \\
\hline & & $(463.9)$ & & & & \\
\hline \multirow[t]{2}{*}{ Total food ${ }^{b}$} & & 1372.3 & & & & \\
\hline & & $(954.6)$ & & & & \\
\hline
\end{tabular}


household intake distribution). The average quantity of fresh milk bought per week per household member was $682 \mathrm{~g}$ and the average quantity of beef $66 \mathrm{~g}$. Fish purchases per member were $44 \mathrm{~g}$, followed by eggs (36 g), beef green offal (27 g) and broiler chicken (27 g).

Additional file 1: Table S1 (see Additional File) reports these figures by the two areas. Overall, the food and ASF expenditures were higher in Dagoretti, which also had a smaller share of households at very low incomes. T-tests indicated that consumption of the more common ASFs (cow's milk, beef products and yoghurt) was higher in Dagoretti. Significantly higher expenditure shares were observed in Korogocho for fish and black pudding. The variation in prices was relatively small with only the price of fish and black pudding significantly lower in Korogocho.

Although a third of households had animals at home, only eight reported consuming ASFs from this source during the week before the survey, which in half of the cases were eggs, in three cases were indigenous chicken and in one case was fresh cows' milk. Six of these eight households reported keeping the animal in town. Three households reported receiving ASFs as a gift, and a further three households brought ASFs home from work or received them as payment for work.

\section{Households' regular ASF consumption and stated reasons for ASF choices}

Figure 1 summarises households' stated reasons for consumption for each of the ASFs under study, among households who reported consuming the specific ASFs regularly. Taste was the most common reason for choosing any of the ASFs with more than $50 \%$ of households stating it as one of the two main reasons for consuming. This was followed by the perceived nutritional value, which was reported for most foods by $30 \%$ or more households, but was particularly high for eggs, cow's yoghurt fish and fresh milk (reported by more than $60 \%$ of consuming households). Price was noted as a reason for consumption by more than $30 \%$ of consuming households for broiler chicken, goat and sheep red offal, black pudding, beef green offal, pork meat and sausage. Tradition was an important factor for consumption of pork sausage, goat and sheep green offal, sheep meat, indigenous chicken and cow's fresh milk (reported by more than $20 \%-30 \%$ of consuming households). Access was an important factor in choice for cow's fermented milk, black pudding, indigenous chicken, beef sausage, goat meat, sheep and pork meat ( $>20 \%-30 \%$ of households).

Reasons stated for not consuming ASFs (Fig. 2) by households who did not report to usually consuming these, were dominated by price, followed by taste and also by the lack of a clear reason for not consuming (i.e., 'don't know' option). Price was the most important reason for not consuming the more common ASFs (beef meat, eggs, fish, and yoghurt). Price was also very strongly emphasised, alongside access as a barrier for consumption of indigenous chicken. Access was further reported by at least more than a fifth of households for sheep and goat fresh milk (74\%), fermented milk (30\%), cow's yoghurt (27\%), sheep meat (31\%), and goat meat (31\%). Risk of disease and hygiene factors were the most prominent reasons for not consuming black pudding (50\% and $60 \%$ of households reporting, respectively) and pork meat (17\% and $26 \%$, respectively), and to lesser extent for other foods. Tradition as a reason for not consuming was reported for most foods by around $20-30 \%$ of households with the exception of beef meat, cow's fresh milk, and indigenous chicken. Interestingly, the perceived nutritional value (not shown on the figure) was reported only by a very small number of households and mostly for goat and sheep offal and cow's fermented milk ( $<3 \%$ of households reporting).

Among the 'other' specified reasons (not presented on the figure), unaffordability and low family income were the most common answers and were mentioned for nearly all ASFs. However, the share of this response was low in comparison to other factors. Beyond income, religion was pointed out by $10 \%$ of households as a reason for not consuming pork meat or sausages. For fish, $8 \%$ of non-consuming households reported smell as a reason for not consuming. Very small numbers of households also responded that allergies were a reason for not consuming eggs, broiler chicken and beef offal. For the latter, one household also reported high use of fuel required for cooking.

\section{Demand elasticities}

The price elasticities of demand for the five aggregated categories of ASFs (beef meat, dairy, fish, eggs and other meats) are presented in Table 3 and estimates from Probit [1] and AIDS [2] models in Additional file 1: Tables S3 and S4 (see additional file). Household demographic variables were generally not associated with either the decision to purchase (probit model) or the expenditure share (AIDS model). Few notable exceptions in the probit model were the share of male adults in the household, which was positively associated with the probability of consuming beef and the total number of household members, which was negatively associated with the probability of consuming fish. Home ownership was associated with lower probability of purchasing fish and 'other meats'.

In the AIDS model we observed that an increase in the number of household members was positively associated with expenditure share of dairy but negatively associated with expenditure share of fish. Having a male household head was positively associated with higher expenditure share of fish. 


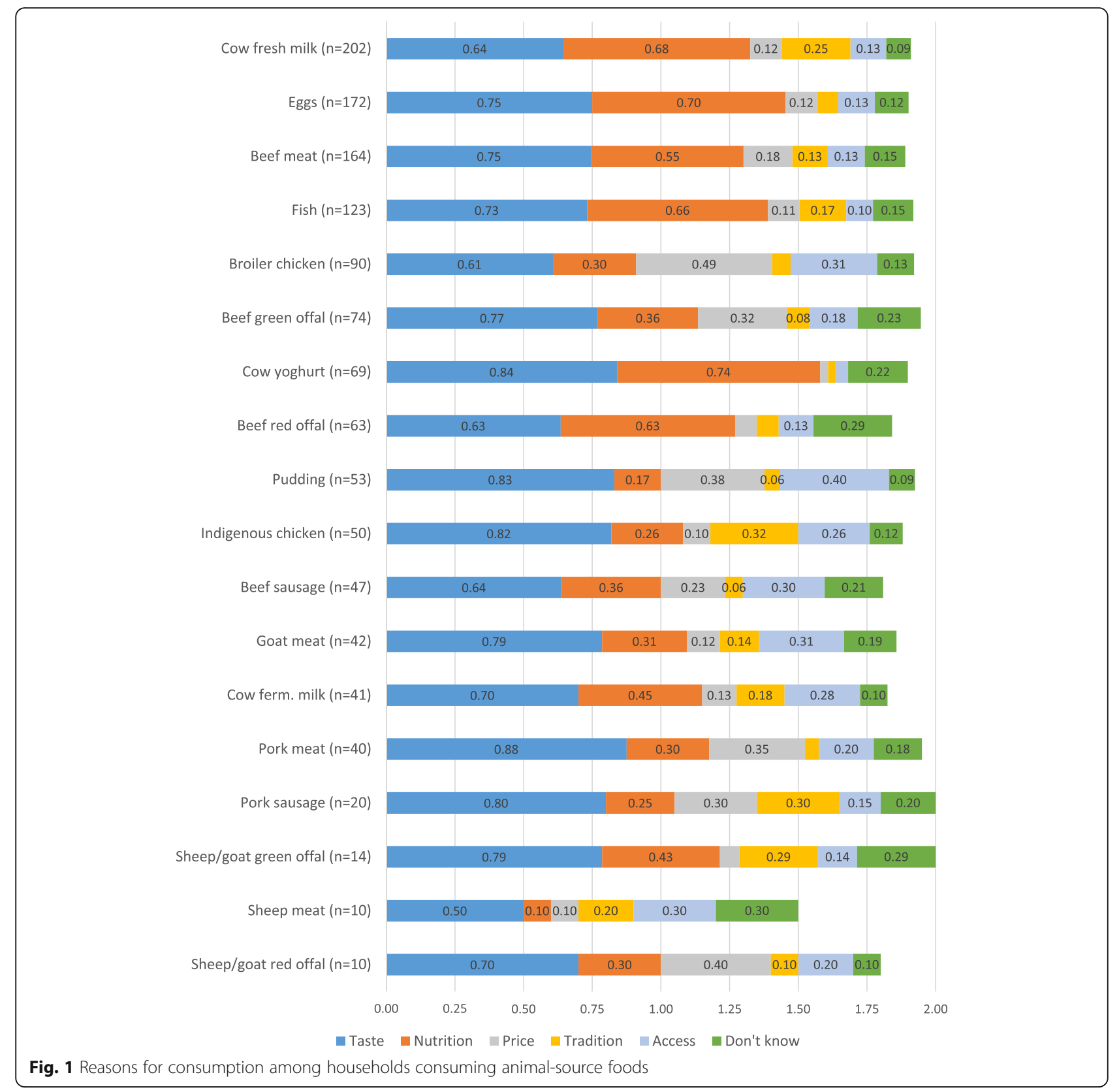

All the own-price elasticity estimates (Table 3, on the diagonal) had the expected negative sign, indicating that an increase in the price of foods was associated with a reduction in its demand. With the exception of eggs, the elasticities for product own-price changes were significant at conventional levels and at relatively similar magnitudes. Demand for beef was least sensitive to price changes with a $10 \%$ price change leading to $9.2 \%$ change in demand, followed by dairy and other meats for which the demand would change by $9.5 \%$. Demand for fish was most sensitive to price changes with an expected $11 \%$ change in demand if price changed by $10 \%$.
Cross-price elasticities (off the diagonal in Table 3), indicate how much the demand for one food changes if the price of another food changes. Positive values show substitution effects meaning that if the price of one product increases (e.g., beef), demand for another product would increase as households' substitute towards the now relatively cheaper product (e.g., dairy). Negative cross-price elasticities show income (complementarity) effects. This means that if the price of one product increases (e.g., beef), the demand for another product decreases (e.g., eggs) as higher price for beef means households have relatively less budget left for buying eggs. 


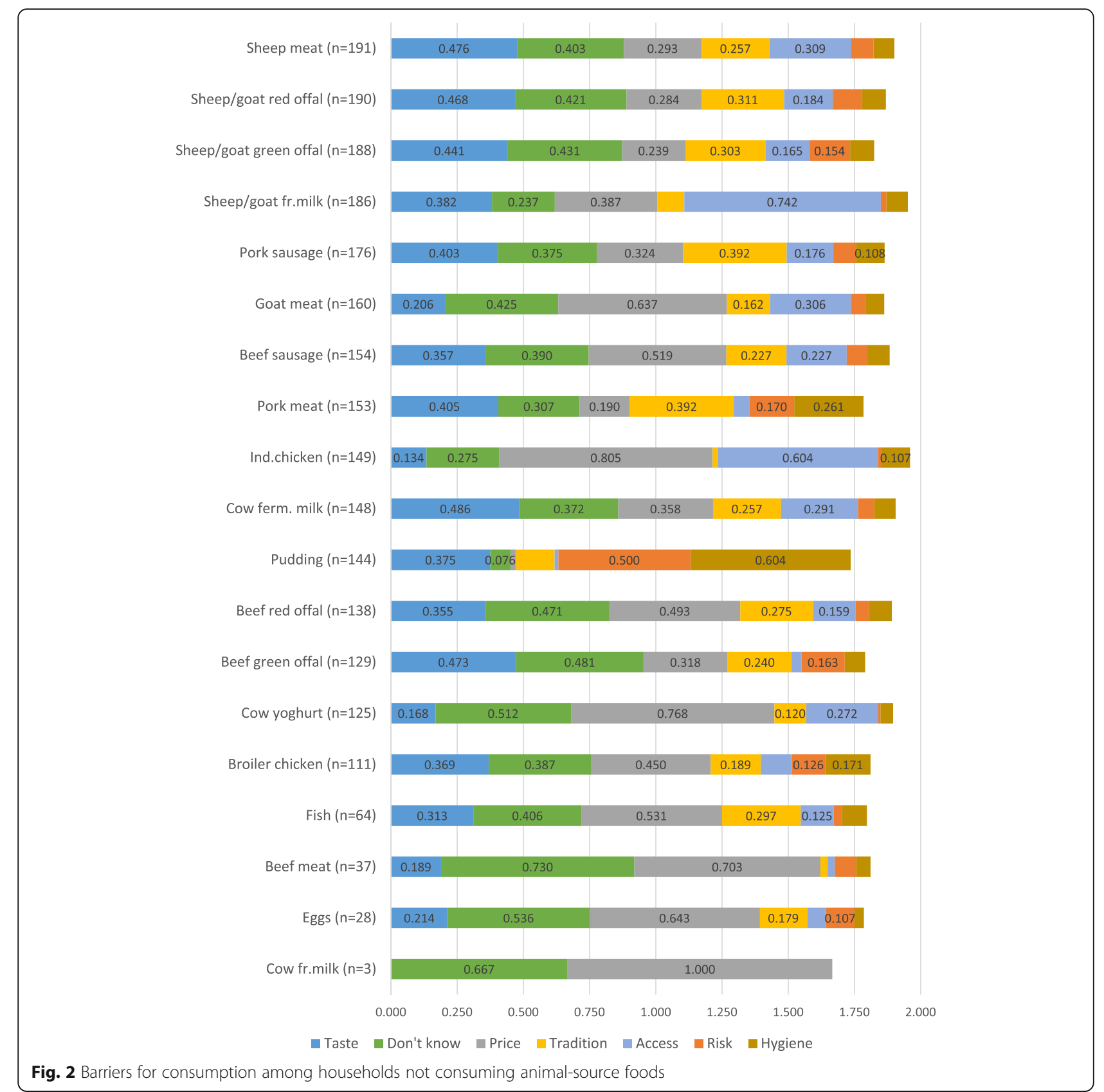

We observed both negative and positive cross-price elasticities. However, only few of the cross-price elasticities were statistically significant $(p<0.1)$ and these were all negative, suggesting income effects. We observed a change in the demand for beef by $1.7 \%$ and by $1.2 \%$ if the price of dairy or other meats was to change by $10 \%$, respectively. A $10 \%$ change in the price of fish was associated with a small $(0.3 \%)$ reduction in the consumption of dairy.

We estimated two demand elasticities with respect to changes in expenditures. First, with respect to changes in total ASF expenditures (e.g., if household ASF expenditures would increase for example via conditional cash transfers for ASF products). Secondly, we estimated demand elasticity with respect to changes in total food expenditure. Overall, an increase in the total food expenditures by $10 \%$ would increase all ASF expenditures by $6.1 \%$. The demand for beef and 'other meats' was most responsive to changes in expenditures in comparison to dairy, fish and eggs.

\section{Discussion}

The aim of this study was to analyse the demand for and drivers and barriers of ASF consumption in poor, 
Table 3 Animal-source foods own- and cross-price elasticities (Marshallian elasticities)

\begin{tabular}{|c|c|c|c|c|c|c|c|}
\hline & \multicolumn{5}{|l|}{ Price } & \multicolumn{2}{|c|}{ Expenditure } \\
\hline & Beef & Dairy & Fish & Eggs & Other meats & $\overline{\text { ASF }}$ & All foods \\
\hline \multirow[t]{2}{*}{ Beef } & $-0.916^{* * *}$ & $-0.165^{* *}$ & -0.027 & -0.050 & $-0.118^{*}$ & $1.28^{* * *}$ & $0.78^{* * *}$ \\
\hline & $(0.229)$ & $(0.085)$ & $(0.070)$ & $(0.221)$ & $(0.068)$ & $(0.17)$ & $(0.10)$ \\
\hline \multirow[t]{2}{*}{ Dairy } & 0.041 & $-0.955^{* * *}$ & $-0.035^{* *}$ & -0.038 & 0.035 & $0.95^{* * *}$ & $0.58^{* * *}$ \\
\hline & (0.059) & $(0.038)$ & $(0.018)$ & $(0.051)$ & $(0.025)$ & $(0.07)$ & $(0.04)$ \\
\hline \multirow[t]{2}{*}{ Fish } & 0.010 & 0.038 & $-1.063^{* * *}$ & 0.063 & 0.082 & $0.87^{* * *}$ & $0.53^{* * *}$ \\
\hline & (0.055) & $(0.065)$ & $(0.101)$ & $(0.055)$ & $(0.08)$ & $(0.08)$ & $(0.05)$ \\
\hline \multirow[t]{2}{*}{ Eggs } & -0.118 & 0.321 & 0.207 & -0.736 & -0.157 & 0.48 & 0.30 \\
\hline & $(0.428)$ & $(0.278)$ & $(0.217)$ & $(0.549)$ & $(0.279)$ & $(0.40)$ & $(0.24)$ \\
\hline \multirow[t]{2}{*}{ Other meats } & -0.107 & -0.115 & 0.050 & -0.072 & $-0.957^{* * *}$ & $1.20 * * *$ & $0.747^{* * *}$ \\
\hline & $(0.068)$ & (0.098) & $(0.052)$ & (0.138) & $(0.131)$ & $(0.11)$ & $(0.07)$ \\
\hline
\end{tabular}

Notes: Standard errors (SE) in parentheses; Marshallian elasticities unconditional on purchase; significant at least ${ }^{*} p<0.1$; ${ }^{* *} p<0.05$, ${ }^{* * *} p<0.01$

densely populated urban areas of Nairobi where malnutrition rates, particularly among children, remain high. In our sample of 205 households stunting affected $42 \%$ of children aged 1-3 years, which is higher than the national average $[1,2]$ and also $74 \%$ of children were identified as anaemic [25]. In the context of relatively high child chronic malnutrition due to inadequate dietary quality, even small increases in ASF consumption could lead to improved health and cognitive outcomes for children $[6,13,17,18,20]$.

Based on the $24 \mathrm{~h}$ recall survey, the households' diet consisted mostly of starchy staples (ugali) and vegetables with relatively low intakes of ASFs [25]. Data on ASF expenditures showed similar levels of consumption of ASFs per household member, to previous reports focusing on low-income settlements or neighbourhoods in Nairobi $[7,15]$. The most common ASFs purchased were fresh cow's milk, eggs and beef meat, equally in line with previous studies $[15,21]$. On average, households purchased $48 \mathrm{~g}$ of ASFs per week per member. If cow's fresh milk was excluded, the purchases of ASFs reduced to $15 \mathrm{~g}$ per week per member. Other sources, such as home grown, gifted, or received for payment ASF were rare. We also detected significant differences between the two areas with lower expenditures and consumption on ASFs in the relatively poorer area of Korogocho.

We first analysed households' stated reasons for consuming or not consuming each of the ASFs. In summary, the main factors behind consumption were taste and perception of nutritional value, followed by price and access. The latter two were reported more frequently for less commonly eaten ASFs (e.g., chicken, offals, processed products), in comparison to more common ASFs (fresh cow's milk, beef, eggs). The main reasons for not consuming ASFs were "price", followed by "taste" or "no clear reason for not consuming". However, for certain ASFs other factors such as having physical access (sheep and goat products, indigenous chicken, fermented milk and yoghurt), tradition (fish, pork products, offal) and food safety (black pudding, pork products, broiler chicken) had a relatively big role. Generally, these findings indicated that price reduction strategy is likely to be effective but with varying impact across the ASFs, in particular for those for which concerns were given regarding safety issues or tradition.

Secondly, we estimated a traditional demand analysis and price and expenditure elasticities for five categories of ASFs (beef meat, dairy, fish, eggs and 'other meats'). The demand for fish was most sensitive to price changes, followed by dairy and other meat category combining the less frequently consumed ASFs. Demand for beef meat was least price sensitive, likely to be reflecting households' preference to it. Price elasticity for eggs also indicated relatively less price sensitive demand but it was not statistically significant at conventional levels. Expenditure elasticity (with respect to total food expenditure) was highest for beef and 'other meats', indicative of preference towards meat and meat products if the food budget were to increase. We observed few significant cross-price income effects showing a reduction in beef consumption if the price of dairy or 'other meats' increased. This suggests that increasing prices for these products might not only reduce its consumption but also the consumption of beef meat, which was one of the main meats consumed. In comparison to previous demand estimates from Kenya, our elasticity estimates were closer to Bett et al. (2012) who equally estimated the demand only for meats [30]. Musyoka et al. (2010) analysed the demand for non-ASF foods as well and found in general higher price sensitivity of the demand [21].

From the policy perspective, in order to reduce prices, interventions could target increasing market competition, supporting small businesses, improving efficiency in transport and the processing systems and minimising 
food wastage along the chain and storage. While in the long run some have argued that poor may actually benefit from higher food prices, it is more likely to be a relevant strategy for households involved in food production rather than net consumers which urban households tend to be $[39,40]$. Different, broader strategies regarding employment and social security could be considered to increase disposable income of households, which would equally improve the affordability of ASFs. Interventions generating income for women are particularly likely to lead to higher food expenditure for the household [41].

Foods for which improvements in supply and physical access could lead to higher consumption included sheep and goat products, yoghurt, and indigenous chicken. Currently, chicken, goat and sheep meat are less available from retailers, which means that households can only access these by buying directly from abattoirs (Alarcon P, Muinde P, Karani M, Akoko J, Kiambi S, Fevre E, Rushton J: Analysis of livestock keeping in Nairobi and the product distribution according to Livestock production officers, forthcoming). As taste was often mentioned for these foods as a reason for consumption, it is likely that if these products were more available and affordable, households would consume these more. Also Juma et al. (2010) found that more than half of households studied living near a slaughterhouse preferred small ruminant meet to beef [22]. Hence, interventions should target the creation of higher and more consistent supply chains, for example via innovations in production technology and facilitation of market outlet expansion [42].

The risk of disease and hygiene factors were in general not a priority concern in explaining non-consumption. One notable exception to this was black pudding, for which the stated concerns over hygiene and risk of disease were likely due to a perceived health risk associated with consuming ruminant blood and offal. If the ASF carries a high risk of being contaminated, then interventions should target improving food safety at processing. If the risk is related to beliefs while the product is actually safe to eat, then consumer education campaigns could decrease this barrier by explaining the nutritional value along with food safety information. Increasing people's knowledge of the nutritional value for products that are not commonly consumed might be particularly effective strategy.

Where consumption is low and taste is a concern (offal, fermented milk, sheep meat, processed meat and pork in this sample), interventions could target cooking and preparation skills, including providing alternative recipes. Tradition was the most often reported demand barrier for pork meat and sausages, which were likely to be related to religious beliefs. Interestingly, when comparing fresh meats, taste was a major driver for pork and goat meat and indigenous chicken consumption, but only for beef this was combined with perceived nutritional benefits.
For most foods, a significant percentage of households could not provide specific reasons for not consuming, which should be further explored, particularly for determining if there is scope for using consumer education strategies to improve the awareness of presence and nutritional values of these foods as an effective way to increase consumption.

When interpreting the findings of this study, there are limitations to take into account. First, the study had a small sample size and a restricted geographical representation at a single point in time (rainy season). For broader policy relevance, such analysis would require larger sample of households to ensure representativeness, including various ethnic backgrounds that may influence the choice of ASFs, as well as longer coverage over time to capture possible seasonal differences in the supply and price of foods. Accuracy of the expenditure data relies on the respondents' ability to recall and also expenditure may not represent intake of ASF if any goes to waste.

Very low consumption of some of the ASFs did not allow estimating the demand for each ASF product and aggregation into the broader groups could have introduced aggregation bias. By looking at only ASFs we focused on the last stage in budgeting which also can cause inconsistencies in price elasticity estimates. While we were able to adjust ASF expenditure elasticities for total food expenditures, we could not apply the same procedure for price elasticities due to missing price information on non-ASFs. First, this limited the interpretability of price elasticities to considering ASF expenditures only, meaning that any changes in ASF prices were assumed to have an impact on the demand for ASFs only, and any changes in non-ASF prices would not affect ASF demand. This is less likely to be the case if non-ASF prices have large fluctuations. Secondly, it could have introduced an error in the estimation itself [31]. While we estimated demand elasticities with respect to changes in total food expenditure, the estimate of total food expenditure was missing for approximately for 30\% of households which could have biased the estimate. Estimating the demand system for food share equations with correction for selection bias using the SY approach provided consistent estimates of the demand system but it might have introduced heterogeneity in the error term which we only addressed by using robust standard errors [34]. We thus recommend caution in citing the price elasticity values.

Low number of households consuming ASF also led to greater uncertainty in interpreting the stated reasons for consuming ASFs. We used a simple approach to understanding the reasons of choice which did not allow predicting trade-offs or willingness-to-pay for each of these attributes. Future research should consider applying utility-theory based applications to eliciting preferences such as conjoint or discrete choice analyses to undrestand drivers a nd barriers of consumption, particularly where observed purchase data is not available. 
Finally, our study assumed equal intra-household allocation of the ASFs. Any inequalities towards children (or different sex of the children) would mean that their consumption of ASFs is even lower [24, 43]. We also did not address the potential impact of increasing ASF consumption on overweight and obesity among adults. In the sample, $29 \%$ of the women were overweight or obese and thus it should be further investigated how policies targeting the consumption of ASFs among malnourished children would affect the nutrition and health outcomes of the adults in the household.

\section{Conclusion}

While affordability was the main consumption barrier of most ASFs, improving consumer knowledge and physical access to a variety of ASFs and addressing food safety issues might help achieving higher levels and diversity of consumption of ASFs which in turn could positively affect children nutrition and health outcomes.

\section{Endnotes}

${ }^{1}$ For a definition of an informal settlement see [44]. Gilbert A. The Return of the Slum: Does Language Matter. International Journal of Urban and Regional Research. 2007; 31:697-713.

${ }^{2}$ The survey questionnaire was pre-piloted among 4 households prior to the survey (excluded from the main survey).

${ }^{3}$ Each section of the survey was administered orally by two experienced and trained local enumerators ( 2 teams of 2 people, with each section always being allocated to same two enumerators).

${ }^{4}$ Called "mutura" in Kenya, the black pudding is made of fried blood and spices stuffed inside intestine.

${ }^{5}$ As the focus of the study was on a detailed level ASF consumption, further surveys of detailed non-ASF expenditures would have proved too demanding for the sample. While the $24 \mathrm{~h}$ recall survey included all foods, it reflects only one day and would be difficult to extrapolate to weekly consumptions to match ASF expenditures.

${ }^{6}$ See Dominguez-Salas (2016) [25] for a detailed description of the sample characteristics.

\section{Additional file}

Additional file 1: The additional_data.pdf includes following supplementary Table S1. Mean expenditure on, quantity bought and unit value of ASFs by area. Table S2. Descriptive statistics of explanatory variables. Table S3. Probit model output. Table S4. AIDS model estimates (IFGNLS). (PDF $495 \mathrm{~kb}$ )

\section{Abbreviations}

AIDS: Almost Ideal Demand System; ASF: Animal-source Foods; CDF: Cumulative Density Function; PDF: Probability Density Function; SY: Shonkweiler and Yen approach

\section{Acknowledgements}

We would like to extend our gratitude in ensuring the success of the project to Kenyan health authorities, the field team (Douglas Angogo, Gideon Mwangi, Judith Mwangangi and Emma Osoro) and the study participants.

\section{Funding}

This project was supported by the CGIAR Research Program on Agriculture for Nutrition and Health (A4NH), led by IFPRI. We also acknowledge the Medical Research Council, Natural Environment Research Council, Economic and Social Research Council, Biotechnology and Biosciences Research Council for the funding received for this project through the Environmental \& Social Ecology of Human Infectious Diseases Initiative (ESEI), Grant Reference: G1100783/1. Further support through partial funding has come from the Leverhulme Centre for Integrative Research on Agriculture and Health (LCIRAH) and the International Livestock Research Institute (ILRI). The APHRC study site is supported by the William and Flora Hewlett foundation (general support), Bill and Melinda Gates foundation (DSS) and SIDA (the Swedish International Development cooperation Agency.

\section{Availability of data and materials}

All data from the study "Investigation of the relationship between livestock value chains and nutritional status of women and children: a pilot study in Kenya" will be made publicly available via ILRI Datasets Portal (https:// data.lli.org/portal/) after all planned analyses and manuscripts are finalised and published. Until then, for enquiries regarding the data and Stata codes used in this study, please contact laura.cornelsen@lshtm.ac.uk or pdominguezsalas@rvc.ac.uk.

\section{Author's contributions}

The author's responsibilities were as follows: JR and PD-S conceived the study design; LC, PD-S, PA, DDA, EF, EMF, DG, BH and JR contributed to the study protocol; PD-S led the data collection; LC performed the statistical analyses and drafted the manuscript. All authors reviewed, commented on, and approved the manuscript. JR and PD-S share the last authorship of the article.

\section{Competing interests}

All authors declare no competing interests.

\section{Consent to publication}

Not applicable.

\section{Ethics and consent to participate}

Ethical approval to conduct the study was obtained from International Livestock Research Institute Institutional Research Ethics Committee in Kenya (ILRIIIREC2013-14), recognised by Kenyan authorities as competent to provide ethical clearance for human research in Kenya, and the Royal Veterinary College Ethics Committee (URN 2013 0093H) in the United Kingdom. Informed written consent was obtained from all respondents after health authorities' approval at the community level. No individual participant data is published.

\section{Author details}

${ }^{1}$ London School of Hygiene and Tropical Medicine, Keppel Street, London WC1E 7HT, UK. ${ }^{2}$ Leverhulme Centre for Integrated Research on Agriculture and Health, 36 Gordon Square, London WC1H OPD, UK. ${ }^{3}$ The Royal Veterinary College, Hawkshead Lane, Hatfield, Hertfordshire AL9 7TA, UK. ${ }^{4}$ African Population and Health Research Center, Nairobi, Kenya. Institute of Infection and Global Health, University of Liverpool, Leahurst Campus, Neston CH64 7TE, UK. International Livestock Research Institute, Nairobi 00100, Kenya.

Received: 15 March 2016 Accepted: 18 November 2016

Published online: 25 November 2016

\section{References}

1. Kimani E. The Nutrition Paradox in Kenya: What Are We Doing? Global Nutrition Report. 2014

2. Masibo P, Makoka D. Trends and determinants of undernutrition among young Kenyan children: Kenya Demographic and Health Survey; 1993, 1998, 2003 and 2008-2009. Public Health Nutr. 2012;15:1715-27. 
3. Olack B, Burke H, Cosmas L, Bamrah S, Dooling K, Feikin D, Talley L, Breiman R. Nutritional status of under-five children living in an informal urban settlement in Nairobi, Kenya. J Health Popul Nutr. 2011;29:357-63.

4. Kimani-Murage E, Muthuri S, Oti S, Mutua M, van de Vijver S, Kyobutungi C. Evidence of a Double Burden of Malnutrition in Urban Poor Settings in Nairobi, Kenya. PlosOne. 2015;10(6):e0129943.

5. Faye O, Baschieri A, Falkingham J, Muindi K. Hunger and food insecurity in Nairobi's slums: an assessment using IRT models. J Urban Health. 2011;88:S235-55.

6. Bwibo N, Neumann C. The Need for Animal Source Foods by Kenyan Children. J Nutr. 2003;133:3936S-40.

7. WFP. Comprehensive food security and vulnerability analysis (CFSVA) and nutrition on assessment Kenya high density urban areas. Kenya: World Food Program; 2012.

8. Kearney J. Food consumption trends and drivers. PhilTransRSoc. 2010;365:2793-807.

9. Thornton P. Livestock Production: recent trends, future prospects. PhilTrans R Soc. 2010;365:2853-67.

10. FAOSTAT. Food Balances; Food Supply - Livestock and Fish Primary Equivalent. FAO. 2016.

11. FAOSTAT. Food secuirty - Indicators from Household Surveys. 2005

12. Gamba P, Kariuki D, Gathigi B. Urban domestic consumption patterns for meat: trends and policy implications. Tegemeo Working Paper 17/2005: Tegemeo Institute of Agricultural Policy and Development. 2005.

13. Neumann C, Harris D, Rogers L. Contribution of animal source foods in improving diet quality and function in children in the developing world. Nutr Res. 2002;22(1):193-220.

14. Smith J, Sones K, Grace D, MacMillan S, Tarawali S, Herrero M. Beyond milk, meat, and eggs: role of livestock in food and nutrition security. Anim Front. 2013;3:6-13.

15. James A, Palmer G. The role of animal source foods in improving nutritional health in urban informal settlements: identification of knowledge gaps and implementation barriers. Int J Child Health Nutr. 2015;4:94-102.

16. Murphy S, Allen L. Nutritional Importance of Animal Source Foods. J Nutr. 2003;133:3932S-5.

17. Dror D, Allen L. The importance of milk and other animal-source foods for children in low-income countries. Food Nutr Bull. 2011;32:227-43.

18. Grillenberger M, Neumann C, Murphy S, Bwibo N, Weiss R, Jiang L, Hautvast JGAJ, West $C$. Intake of micronutrients high in animal-source foods is associated with better growth in rural Kenyan school children. $\mathrm{Br} J$ Nutr. 2006;95:379-90.

19. Jin M, lannotti L. Livestock production, animal source food intake, and young child growth: The role of gender for ensuring nutrition impacts. Soc Sci Med. 2014;105:16-21.

20. Neumann C, Murphy S, Gewa C, Grillenberger M, Bwibo N. Meat Supplementation Improves Growth, Cognitive, and Behavioral Outcomes in Kenyan Children. J Nutr. 2003;113:1119-23.

21. Musyoka MP, Lagat JK, Ouma DE, Wambua T, Gamba P. Structure and properties of urban household food demand in Nairobi, Kenya: implications for urban food secuirty. Food Sec. 2010;2:179-93.

22. Juma GP, Ngigi M, Baltenweck I, Drucker AG. Consumer demand for sheep and goat meat in Kenya. Small Rumin Res. 2010;90:135-8.

23. Fessler D, Navarrete C. Meat Is Good to Taboo: Dietary Proscriptions as a Product of the Interaction of Psychological Mechanisms and Social Processes. J Cogn Cult. 2003;3:1-40.

24. Oniang R, Mutuku J, Malaba S. Contemporary African food habits and their nutritional and health implications. Asia Pacific J Clin Nutr. 2003:12:231-6.

25. Domínguez-Salas P, Alarcón P, Häsler B, Dohoo I, Colverson K, KimaniMurage E, Alonso S, Ferguson E, Fevre E, Rushton J, Grace D. Nutritional characterisation of low-income households of Nairobi: socioeconomic livestock and gender considerations and predictors of malnutrition from a cross-sectional survey. BMC Nutr. 2016;2:47.

26. Cox T, Wohlgenant M. Prices and quality effects in cross-sectional demand analysis. Am J Agric Econ. 1986;68:908-19.

27. Heien DM, Wessells CR. Demand systems estimation with microdata: a censored regression approach. J Bus Econ Stat. 1990;8:365-71.

28. Shonkwiler J, Yen S. Two-step estimation of censroed system of equations. Am J Agric Econ. 1999;81:972-82.

29. Deaton A, Muellbauer J. An almost ideal demand system. Am Econ Rev. 1980;70:312-26.

30. Bett HK, Musyoka MP, Peters KJ, Bokelmann W. Demand for meat in the rural and urban areas of Kenya: a focus on the indigenous chicken. Econ Res Int. 2012;2012:1-10.
31. Edgerton DL. Weak separability and the estimation of elasticities in multistage demand systems. Am J Agric Econ. 1997;79:62-79.

32. Moschini GC. Units of Measurement and the Stone Index in Demand Systems Estimation. Am J Agric Econ. 1995;77(1):63-8.

33. Blundell R, Robin JM. Estimation in Large and Disaggregated Demand Systems: An Estimator for Conditionally Linear Systems. J Appl Economet. 1999;14:209-32

34. Yen S, Kan K, Su S-J. Household demand for fats and oils: two-step estimation of a censored demand system. Appl Econ. 2002;14:1799-806.

35. Ecker O, Qaim M. Analyzing Nutritional Impacts of Policies: an Empirical Study for Malawi. World Dev. 2011;39:42-28.

36. Yen S, Fang C, Su S-J. Household food demand in urb an China: a censored system approach. J Comp Econ. 2004;24:564-85.

37. Yen S, Lin B-H. A sample selection approach to censored demand systems. Am J Agric Econ. 2006:88:742-9.

38. Kenya facts and figures [http://www.usaid.gov/sites/default/files/documents/ 1860/9)\%20Kenya\%20facts\%20and\%20figures\%202012.pdf]

39. Heady D. Food prices and poverty reduction in the long run, IFPRI Discussion paper 01331. 2014.

40. Ivanic M, Martin W. Implications of higher global food prices for poverty in low-income countries. Agric Econ. 2008;39:405-16.

41. van den Bold M, Quisumbing A, Gillespie S. Women's Empowerment and Nutrition. An Evidence Review, IFPRI Discussion paper 01294. Washington DC: International Food Policy and Research Institute (IFPRI); 2013.

42. de Brauw A, Gelli A, Allen S. Identifying opportunities for nutrition-sensitive value-chain interventions, IFPRI Research Brief No 21; June 2015. 2015.

43. Ndiku M, Jaceldo-Siegl K, Singh P, Sabate J. Gender inequality in food intake and nutritional status of children under 5 years old in rural Eastern Kenya. Eur J Clin Nutr. 2011;65:26-31.

44. Gilbert A. The Return of the Slum: Does Language Matter. Int I Urban Reg Res. 2007:31:697-713.

\section{Submit your next manuscript to BioMed Central and we will help you at every step:}

- We accept pre-submission inquiries

- Our selector tool helps you to find the most relevant journal

- We provide round the clock customer support

- Convenient online submission

- Thorough peer review

- Inclusion in PubMed and all major indexing services

- Maximum visibility for your research

Submit your manuscript at www.biomedcentral.com/submit
) Biomed Central 